\title{
APROVEITAMENTO INTEGRAL DOS ALIMENTOS ENTRE ACADÊMICOS DE UMA FACULDADE PARTICULAR DO DF
}

\author{
Fernanda Laignier Gonçalves ${ }^{1}$ \\ Andréia Araújo Lima Torres ${ }^{2}$
}

\begin{abstract}
Resumo: Foi realizado um estudo transversal entre alunos de uma faculdade particular do DF com o objetivo de avaliar a visão dos mesmos sobre o aproveitamento integral dos alimentos. A amostra foi constituída por 319 alunos (23\% do total de indivíduos matriculados na instituição de ensino), sendo 195 (61 \%) do sexo feminino e 124 (39 \%) do sexo masculino. Os mesmos preencheram um questionário auto aplicativo com 10 questões, onde foi constatado que muitos dos alunos não conhecem os projetos que trabalham com aproveitamento integral dos alimentos, porém não existe preconceito quanto ao consumo desses alimentos sendo que grande parte relatou que já preparou alguma receita aproveitando os alimentos em sua totalidade e que gostaram muito. Ainda há muita dúvida quanto à forma correta de higienização destes alimentos mostrando a necessidade de uma maior divulgação do preparo da solução clorada para que seja utilizada de forma mais intensa entre a população. Conforme esperado os alunos de nutrição demonstraram um nível maior de informações a respeito do tema pesquisado, resultado este que se deve ao próprio curso onde são estudados todos os assuntos abordados na pesquisa.
\end{abstract}

\section{Palavras Chaves: Aproveitamento integral, Alimentos, Acadêmicos.}

Abstract: We conducted a study among students at a private college of the City with the aim of evaluating the vision of taking full advantage of the food between them. It was used a self applied questionnaire containing 10 questions mixed up and distributed by the researcher. From a sample of 319 (23\% of the registered and effective students), 195 (61\%) were female and 124 (39\%) were male. It was also observed where it was found that many students are unaware of projects working with full use of food, but there is no bias regarding the consumption of these foods is that most reported that revenue has already prepared some taking advantage of the food in its entirety and enjoyed very much. There is still much doubt about the correct way of cleaning these foods showing the need for greater disclosure of the preparation of chlorine solution to be used more intensively between the expected populace. Conform nutrition students achieved a higher level information about the research topic, a result that is due to the very course where they studied all the subjects covered in the survey.

\footnotetext{
${ }^{1}$ Nutricionista, Pós-Graduanda do Curso de Educação e Promoção da Saúde da Universidade de Brasília - UnB. ${ }^{2}$ Nutricionista, Orientadora Prof. Msc. Em Nutrição Humana pela Universidade de Brasília -UnB.
} 


\section{1-Introdução:}

O ser humano se alimenta com a finalidade de satisfazer necessidades básicas como absorver substâncias que lhe são essenciais e obter energia para a manutenção de suas funções vitais (MOURA e VILELA, 2009). A ingestão do alimento correto e nas quantidades ideais, seguindo bons hábitos de dieta durante toda a vida, significa um corpo e uma mente mais saudável, maior vitalidade e energia, além de maior resistência às doenças, maior longevidade (BRADACZ, 2003).

Neste contexto, o aproveitamento integral dos alimentos tem sido bastante discutido por sua abrangência e devido às qualidades nutritivas de cascas, talos e folhas. O uso de tais alimentos também leva à maior economia e à redução do desperdício e poluição ambiental (TEIXEIRA, et al. 2002). Mesmo com todos estes benefícios, vê-se ainda a necessidade de criar estratégias e mecanismos que favoreçam o aproveitamento de todo alimento produzido, reduzindo-se, desta forma, o desperdício e conseqüentemente a fome (GONÇALVES, 2005).

Atualmente as intercorrências econômicas tem sido para a população um obstáculo na aquisição de alimentos adequados para serem consumidos, e motivo de preocupação cotidiana entre as pessoas. O aproveitamento integral dos alimentos é uma nova vertente na área de alimentação que precisa ser mais divulgada. Sabe-se que esta informação ainda é escassa, interessante também é frisar que a fome e o desperdício de alimentos são dois dos maiores problemas que o Brasil enfrenta, e este um dos paradoxos de nosso país. Produzimos 140 milhões de toneladas de alimentos por ano, estamos entre os maiores exportadores de produtos agrícolas do mundo e, ao mesmo tempo, temos inúmeras pessoas sem acesso ao alimento em quantidade e/ou qualidade suficiente (GONDIM et al.,2005).

Um dos benefícios do aproveitamento integral dos alimentos seria corrigir e complementar a alimentação do brasileiro. Vê-se que mesmo com a alta produção de alimentos a alimentação do brasileiro apresenta padrões incorretos e desarmônicos, necessitando ser melhorado e modificado por meio de um trabalho de conscientização com a população a respeito de uma alimentação equilibrada (MEZOMO, 2002). Para Moura e Vilela (2009), uma alimentação equilibrada é aquela que atende as necessidades nutricionais do indivíduo harmonicamente.

Segundo Ferreira et al. (2007), a falta de informação sobre as propriedades nutricionais dos alimentos proporciona o desperdício de toneladas de recursos alimentares, sendo que o Brasil é um dos países onde mais se pratica o ato do desperdício, recursos naturais, financeiros e até alimentos são simplesmente atirados no lixo. O desperdício está inserido na cultura brasileira, portanto esta idéia dificilmente será transformada, o que acaba afetando a produção do país como um todo, resultando em prejuízos para toda a sociedade (BORGES, 1991, p.124 apud AUGUSTINI, 2008, p.99). Também segundo Parisenti, Firmino e Gomes (2008), estes desperdícios acumulam perdas de aproximadamente 30\% durante toda cadeia produtiva. Isto é muito grave uma vez que desperdiçar é o mesmo que extraviar o que pode ser aproveitado para benefício de outras pessoas (VAZ, 2006).

Observa-se então um campo de inserção onde o nutricionista deveria estar muito atuante a fim de conscientizar a população sobre o uso correto do alimento. $O$ aproveitamento integral possui como princípio básico a diversidade e a complementação de refeições, objetivando sempre reduzir custos, proporcionar preparo rápido e paladar regionalizado (SESC, 2003). Pode-se observar uma maior adesão a este modo 
alternativo de se alimentar, principalmente dentre as classes sociais mais populares (SOUZA et al., 2007).

Vale ressaltar que a higiene destes alimentos deve ser observada, pois a lavagem dos vegetais é a prática mais comum para se obter um produto mais seguro sendo que água deve ser de boa qualidade para que não se transforme em fonte de contaminação no processo de higienização. A eficácia desta operação pode ser intensificada com a utilização de antimicrobianos ou desinfetantes nessa água de lavagem (BERBARI; PASCHOALINO; SILVEIRA, 2001).

Tendo em vista esta perspectiva o presente trabalho objetivou avaliar a visão e conhecimento acerca do aproveitamento integral dos alimentos entre acadêmicos de uma faculdade particular do DF.

\section{Metodologia}

Foi realizado um estudo transversal entre uma população alvo de 1.351 estudantes de uma faculdade particular do DF. Os critérios de inclusão no presente estudo foram alunos de ambos os sexos com idade acima de18 anos, matriculados e freqüentando às aulas nos turnos matutino e vespertino. Foram automaticamente excluídos da pesquisa os alunos que não estiveram presentes no dia da coleta dos dados e os menores de 18 anos. Também foram excluídos os alunos que não tiveram interesse em participar ou que não assinaram o termo de consentimento livre e esclarecido.

O Instrumento utilizado para coleta dos dados foi um questionário auto aplicativo com 10 questões mistas, elaborado e distribuído pela própria pesquisadora. As questões referiam-se a noção sobre aproveitamento integral dos alimentos indagando sobre recebimento de orientação a respeito do assunto, o conhecimento de algum projeto que trabalhe com tal questão, higiene adequada dos alimentos já que estes são aproveitados com cascas, talos e sementes, a preparação de alguma receita, entre outras.

Foram distribuídos 847 questionários, sendo devolvidos preenchidos 427, e eliminados da amostra 108 em decorrência de preenchimento incompleto ou inadequado. Vale ressaltar que são 1.351 alunos matriculados e efetivos, portanto a amostra utilizada reflete $23 \%$ da população alvo. Obteve-se uma amostra constituída por 319 pessoas, sendo 195 (61 \%) do sexo feminino e 124 (39 \%) do sexo masculino.

Após aprovação do projeto pela Comissão de Ética da Universidade de Brasília, o questionário apresentado foi aplicado entre os alunos que ao receberem esclarecimentos sobre a pesquisa consentiram em responder ao questionário.

\section{3-Resultados e Discussão}

Do total de alunos que participantes $(n=319)$ da pesquisa, 61\% (195) eram do sexo feminino e 39\% (124) eram do sexo masculino (Figura 1). Participaram deste estudo 40 alunos do curso de nutrição e 279 dos demais cursos existentes na Faculdade. 


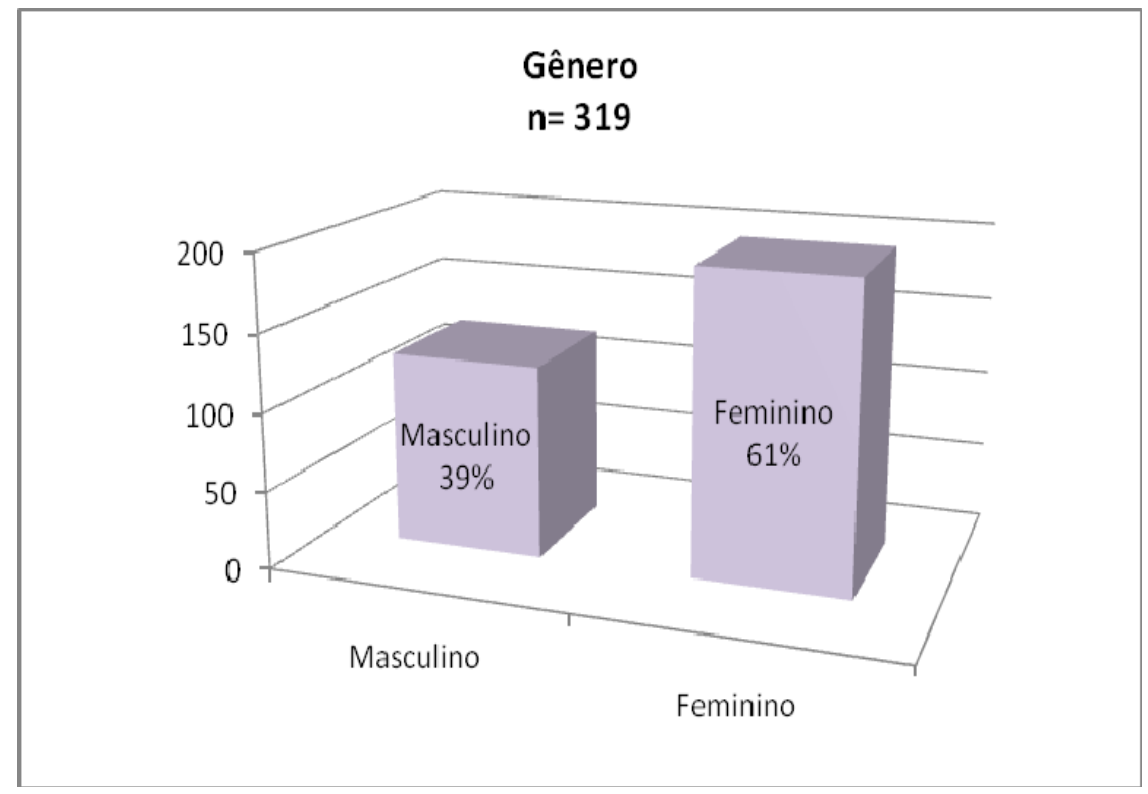

FIGURA 1- Distribuição da amostra por gênero

Quanto ao conhecimento de algum projeto que trabalhe com aproveitamento integral, 33 alunos (97\%) dos alunos do curso de nutrição relataram conhecer algum projeto neste sentido, enquanto 231 alunos (82\%) dos demais cursos responderam que não conheciam nenhum projeto. A inciativa mais citada (84\%) foi o projeto Mesa Brasil do SESC. Este resultado reflete uma baixa divulgação dos demais projetos existentes para que os alimentos sejam melhor aproveitados e se evite desperdícios (FIGURA 2).

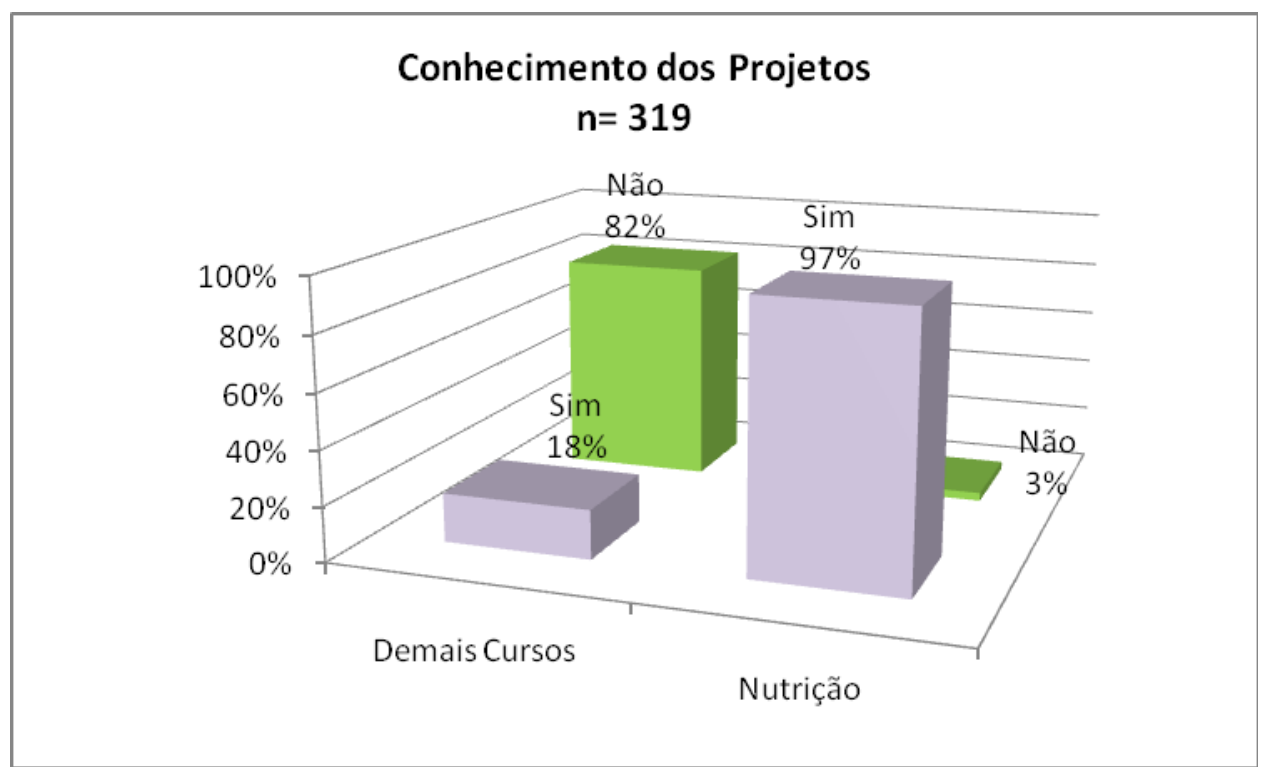

FIGURA 2 - Conhecimento dos Projetos

Os achados da Figura 3, contrariam em parte o que afirma Souza e colaboradores (2007), em seu estudo que diz que a cultura e o preconceito impedem a utilização das cascas, talos e sementes dos alimentos. Entre os alunos de nutrição 98\% responderam que não alentam qualquer tipo de preconceito contra essa forma de alimentação. Entre os alunos dos demais cursos esse número encontra-se bem próximo registrando essa negativa entre $95 \%$ dos entrevistados. Entre os alunos que 
afirmaram ter algum tipo de preconceito a opção mais marcada foi a que não gostavam do sabor das preparações. Segundo Mezomo (2002), o preconceito diz respeito às características organolépticas e ao modo de preparar os alimentos.

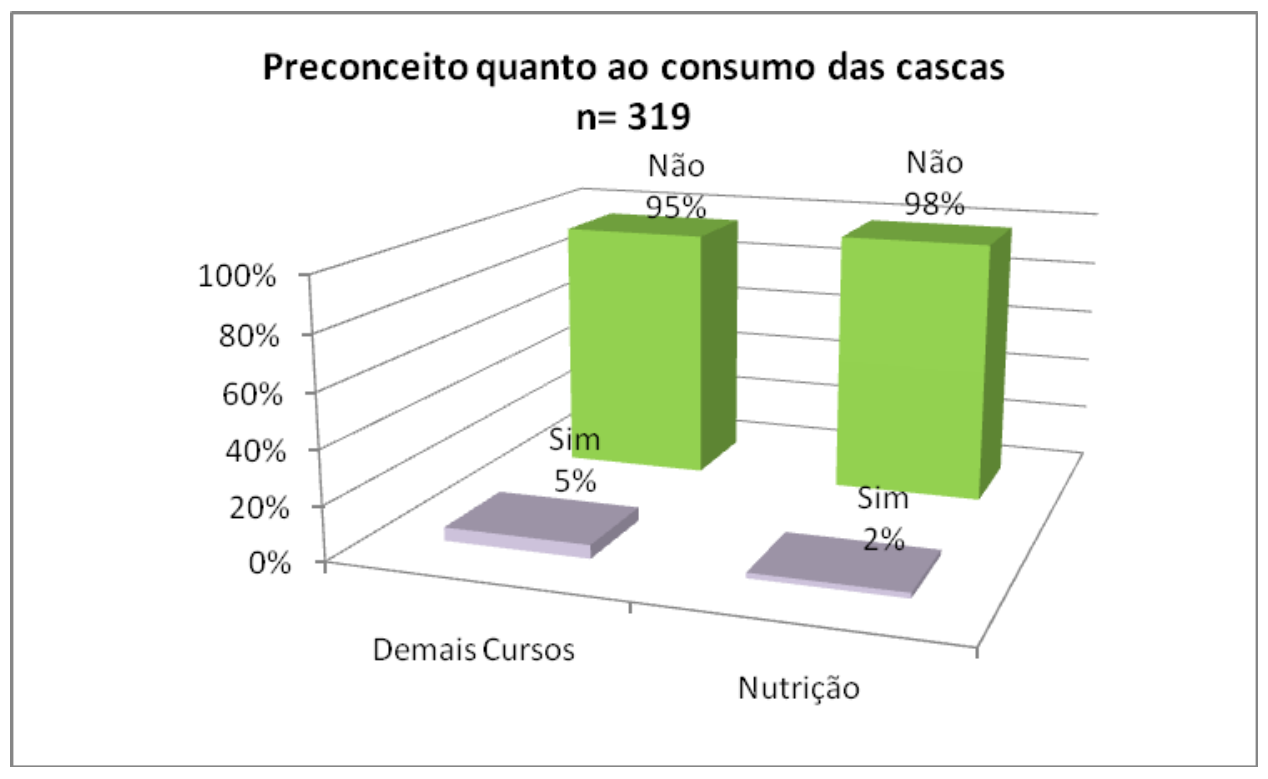

FIGURA 3 - Preconceito quanto ao consumo das cascas de frutas e legumes nas refeições.

Quando questionados sobre o recebimento de alguma orientação sobre como os alimentos poderiam ser aproveitados em sua totalidade, 97,5\% dos alunos do curso de nutrição responderam já terem sido orientados e entre estes $46 \%$ afirmaram terem sido orientados por nutricionista. Entre os alunos dos demais cursos, $58 \%$ afirmaram terem sido orientados sendo que $30 \%$ por nutricionista e $20 \%$ por outros meios como internet e televisão.

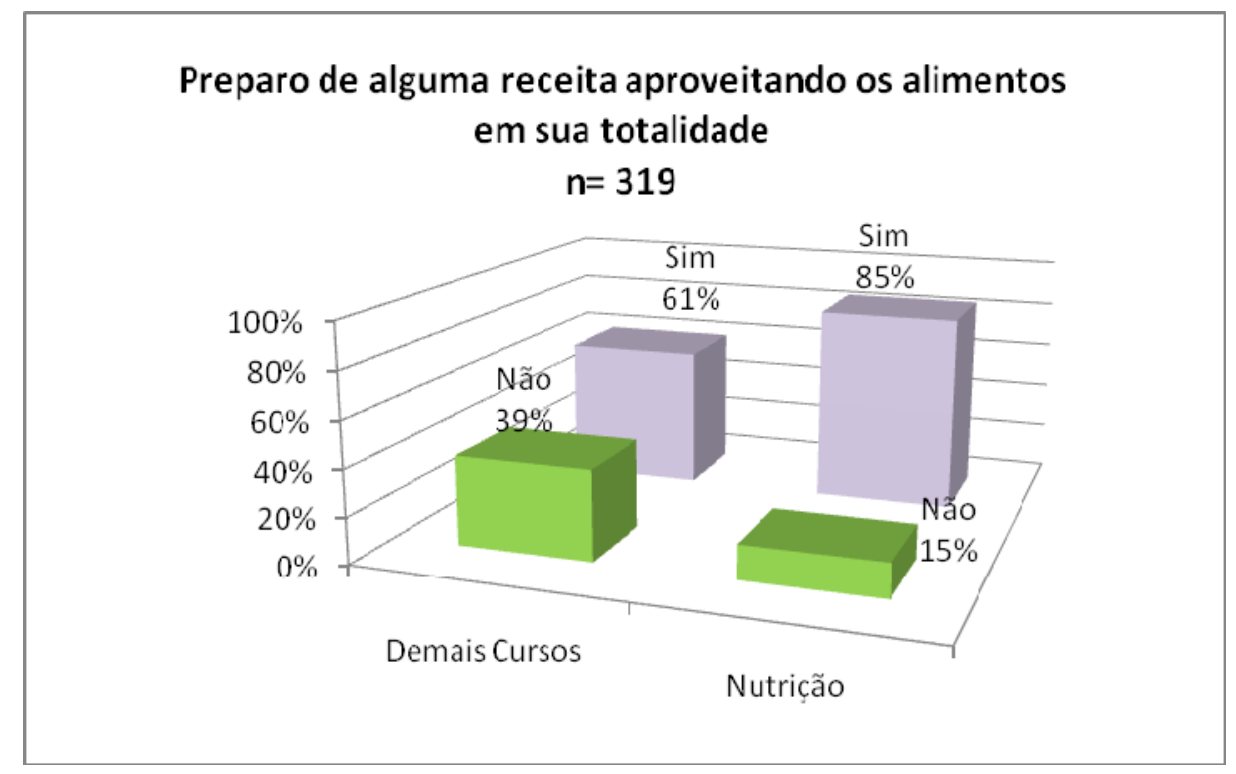

Figura 4 - Preparo de alguma receita aproveitando os alimentos em sua totalidade.

Quanto ao preparo de alguma receita aproveitando as cascas, talos ou sementes dos alimentos (figura 4), 61\% dos alunos dos demais cursos responderam 
afirmativamente a esta questão e $85 \%$ dos alunos de nutrição também afirmaram ter feito alguma preparação utilizando os alimentos em sua totalidade, resultado este que se deve em grande parte ao trabalho de nutricionistas que divulgam essa prática.

Souza e colaboradores (2007), citam que as folhas da couve-flor, embora sejam um pouco mais duras, contém mais ferro do que a couve manteiga e são mais nutritivas do que a própria couve-flor, podem ser consumidas, assim como as folhagens de cenoura e de beterraba que podem ser ingeridas na forma de saladas ou refogadas sendo abundantes em minerais. É interessante utilizar os alimentos em sua totalidade, a casca do pepino pode ser transformada em picles, a casca do abacaxi na preparação de refresco, das cascas de melancia, banana, mamão, manga, podem ser elaborados doces, geléias ou compotas (SOUZA et al., 2007). Existem várias formas de preparações para que os alimentos sejam aproveitados em sua totalidade, sendo mais relevante que ingestão desses seja realizada.

Vários produtos industrializados são obtidos a partir do processamento de frutas que acabam produzindo grandes quantidades de resíduos que são transformados em ração animal, usados como adubo ou são descartados no meio ambiente aumentando assim a poluição ambiental. Estes resíduos podem atingir até $70 \%$ do peso total dos frutos. Após um estudo do aproveitamento de cascas de maracujá em forma de doces em calda, os resultados demonstraram a viabilidade em utilizar esta prática (SANTANA e OLIVEIRA, 2005). A divulgação destas informações auxilia na conscientização da sociedade estimulando a prática do desenvolvimento sustentável.

A casca do maracujá, por exemplo, é rica em fibra solúvel, possuindo propriedades funcionais como a redução dos níveis de colesterol e diabetes, proporcionando melhor funcionamento gastrintestinal, e, podendo ser utilizada na preparação de produtos de panificação (CORDOVA et. al., 2005, apud SANTOS, 2008). Esta estratégia é muito interessante, já que a baixa ingestão de fibras na dieta vem sendo associada ao crescimento das doenças crônicas não transmissíveis como diabetes mellitus e dislipidemias (CERQUEIRA, 2008).

A casca de outros alimentos também são extremamente nutritivas. Segundo Fernandes e colaboradores (2008), a casca da batata inglesa que regularmente é descartada também pode ser transformada em farinha e utilizada em produtos de panificação. Encontra-se também maiores quantidades de proteínas, fibras e minerais na casca da banana do que na própria polpa. A casca deste fruto é considerada comestível, representando em média 48\% do peso da fruta (MENDONÇA et al.,2006, apud FERREIRA et al., 2007) e se descartada despreza-se grande parte dos nutrientes que poderiam se aproveitados em benefício de pessoas que se interessam por tal prática.

Ao pesquisar os resíduos de frutas utilizadas para extração da polpa, Uchoa e colaboradores (2008), observaram que os pós alimentícios derivados de caju, goiaba e maracujá são fontes importantes de vitamina $C$ e apresentam alto índice de fibra bruta e alimentar, portanto, também podem ser aproveitados na formulação de novos produtos alimentícios como biscoitos, bolachas, pães e sopas. (Tabela 1).

A respeito da aceitação da preparação o resultado foi bastante satisfatório 
| Tabela 1: Aceitação da preparação.

\begin{tabular}{l|c|c}
\hline & Demais Cursos & Nutrição \\
\hline Gostei extremamente & $12,86 \%$ & $23,52 \%$ \\
\hline Gostei muito & $60,81 \%$ & $73,52 \%$ \\
\hline Desgostei ligeiramente & $6,43 \%$ & ---- \\
\hline $\begin{array}{l}\text { Não gostei nem } \\
\text { desgostei }\end{array}$ & $16,95 \%$ & --- \\
\hline $\begin{array}{l}\text { Desgostei } \\
\text { moderadamente }\end{array}$ & $2,33 \%$ & $2,94 \%$ \\
\hline $\begin{array}{l}\text { Marcou mais de uma } \\
\text { opção }\end{array}$ & $0,58 \%$ & ---- \\
\hline
\end{tabular}

Pode-se perceber a boa aceitação das preparações elaboradas, não obstante restanos tornar estas preparações um hábito onde estes alimentos possam ser consumidos com maior frequência. Em estudo realizado por Souza e colaboradores (2007), foi feita análise sensorial e nutricional de tortas salgadas elaboradas através do aproveitamento de talos e cascas de hortaliças e o que se pode observar foi uma boa aceitação em relação ao sabor, aparência, textura e cor.

Dos alunos que responderam afirmativamente a questão da preparação de alguma receita aproveitando os alimentos totalmente, $41,17 \%$ dos alunos de nutrição responderam ter elaborado alguma preparação em cursos e $33 \%$ destes prepararam alguma receita em casa. Dos alunos dos demais cursos apenas 5,26\% afirmaram ter preparado alguma receita em cursos e $87 \%$ prepararam no próprio domicílio.

Quando questionados como habitualmente preparam seus alimentos 63\% dos alunos dos demais cursos responderam que aproveitam alguns talos, sementes e cascas e $17 \%$ responderam que retiram todos os talos sementes e cascas, tal resultado demonstra a necessidade de um trabalho de educação nutricional de forma efetiva entre os acadêmicos (Tabela 2), pois o hábito da utilização dos vegetais em sua totalidade aumenta a disponibilidade de nutrientes e a variedade alimentar na dieta do brasileiro, elevando também o aporte de fibras, vitaminas, minerais (SOUZA et al.,2007). Por isto, o aproveitamento integral dos alimentos deveria ser praticado pela sociedade em geral independente do nível sócio econômico, visto que o Brasil encontra-se entre os dez países que mais se desperdiça alimentos no mundo (GOULART, 2006).

Tabela 2 : Como habitualmente prepara o alimentos.

\begin{tabular}{l|c|c}
\hline & Demais Cursos & Nutrição \\
\hline $\begin{array}{l}\text { Retiro todos os talos, } \\
\text { sementes e cascas }\end{array}$ & $17 \%$ & $2 \%$ \\
\hline $\begin{array}{l}\text { Aproveito todos os } \\
\text { talos, sementes e } \\
\text { cascas }\end{array}$ & $10 \%$ & $7 \%$ \\
\hline $\begin{array}{l}\text { Aproveito alguns } \\
\text { talos sementes e } \\
\text { cascas }\end{array}$ & $63 \%$ & $80 \%$ \\
\hline Outros & $6 \%$ & $3 \%$ \\
\hline Sem resposta & $4 \%$ & $8 \%$ \\
\hline
\end{tabular}

Também é importante considerar que para o consumo destes alimentos a higienização adequada é extremamente importante, visto que vegetais possuem elevado risco de contaminação por parasitas e microorganismos. Isto acarreta prejuízos, pois o número de surtos associados a este grupo de alimentos tem sido associado à higienização inadequada (CARDOSO; et al., 2005). Segue abaixo os resultados relacionados a higiene adequada dos alimentos (Tabela 3). 
Tabela 3 : Higiene adequada dos alimentos

\begin{tabular}{c|c|c}
\hline & Demais Cursos & Nutrição \\
\hline $\begin{array}{c}\text { Lavar somente com } \\
\text { água }\end{array}$ & $14 \%$ & $5 \%$ \\
\hline $\begin{array}{c}\text { Lavar com água e } \\
\text { sabão }\end{array}$ & $20 \%$ & --- \\
\hline $\begin{array}{c}\text { Lavar com água e } \\
\text { vinagre }\end{array}$ & $33 \%$ & $5 \%$ \\
\hline $\begin{array}{c}\text { Lavar com água e } \\
\text { cloro }\end{array}$ & $26 \%$ & $90 \%$ \\
\hline $\begin{array}{c}\text { Sem resposta } \\
\text { Marcou mais de uma } \\
\text { opção }\end{array}$ & $2 \%$ & -- \\
\hline
\end{tabular}

Observa-se que apenas $26 \%$ dos alunos dos demais cursos fazem o uso de soluções cloradas. As soluções desinfetantes a base de cloro são compostos eficientes e de baixo custo podendo ser usado no controle bacteriológico de frutas e hortaliças (BERBARI; PASCHOALINO; SILVEIRA, 2001). Considerando o exigido pela RDC $\mathrm{n}^{\circ}$ 352, de 23 de dezembro de 2002, as frutas e ou hortaliças devem ser lavadas em água potável adicionada de solução clorada, porém esta informação é difundida em maior proporção entre os alunos de nutrição, necessitando ter uma atenção maior entre os alunos dos demais cursos que responderam em sua maioria que a higienização adequada dos vegetais é realizada com água e vinagre.

\section{4- Conclusão:}

O consumo dos alimentos em sua totalidade tem sido difundido por meio da mídia em geral aliada ao trabalho de nutricionistas em todo país; porém é sabido que o mesmo ainda é insuficiente. Por isto, para divulgar um método de alimentação diferente do convencional, onde se aproveita o alimento em sua integralidade é necessário que o profissional nutricionista quem detém maior conhecimento nesta área, se empenhe em ensinar a preparar estes alimentos, já que o presente estudo constatou que o preconceito não é barreira para que estes alimentos sejam consumidos.

Assim, torna-se necessária a realização de um programa de educação nutricional entre os alunos para que eles conheçam o que é desperdiçado no Brasil e sejam estimulados a consumir os alimentos de forma integral, pois esta alimentação rica em nutrientes reduz o desperdício e estimula o desenvolvimento sustentável.

Foi observado também que ainda há muita dúvida quanto à forma correta de higienização destes alimentos mostrando a necessidade de uma maior divulgação do preparo da solução clorada para que seja utilizada de forma mais intensa entre a população. Também foi visto a necessidade de maiores pesquisas quanto à disponibilidade de nutrientes destes alimentos, afim de que se estabeleçam as quantidades máximas a serem utilizadas diariamente.

Conforme esperado os alunos de nutrição obtiveram um nível maior de informações a respeito do tema pesquisado, resultado este que se deve ao próprio curso onde são estudados todos os assuntos abordados na pesquisa. 


\section{5- Referências Bibliográficas:}

AUGUSTINI, V. C. de M. et al. Avaliação do índice de resto-ingesta e sobras em Unidade de Alimentação e Nutrição (UAN) de uma empresa metalúrgica na cidade de Piracicaba/SP. Rev. Simbio-Logias. São Paulo. v.1, n.1, p. 99-110, maio, 2008.

ANVISA. $\quad$ RDC $352 . \quad$ Disponível em http://www.anvisa.gov.br/legis/resol/2002/352_02rdc.pdf > Acesso em 24/11/2009.

Banco de Alimentos e Colheita Urbana: Aproveitamento Integral dos Alimentos. Rio de Janeiro: SESC/DN, 2003. 45 p. Disponível em: http:www.sescsp.org.br> Acesso em 20/07/2009.

BERBARI, S. A. G.; PASCHOALINO, J.E.; SILVEIRA. N. F. A. Efeito do cloro na água de lavagem para desinfecção de alface minimamente processada. Ciênc. Tecnol. Aliment., Campinas, v.21 n.2 p.197-201, maio, 2001.

BRADACZ, D.C. Modelo de gestão da qualidade para o controle de desperdício de alimentos em unidades de alimentação e nutrição. 2003. (Dissertação). (Mestrado em Engenharia de Produção), Universidade Federal de Santa Catarina, Florianópolis.

CANESQUI, A. M. A qualidade dos alimentos: análise de algumas categorias da dietética popular. Rev. Nutr., Campinas, v.20 n.2 p.203-216, mar., 2007.

CARDOSO, R.C.V., et al, Unidades de alimentação e nutrição nos campi da universidade federal da Bahia: Um estudo sob a perspectiva do alimento seguro. Rev. Nutr., Campinas, v.18, n.5, p. 669-680, set., 2005.

CERQUEIRA, P. M., et al, Efeito da farinha de semente de abóbora (Cucurbita maxima, L.) sobre o metabolismo glicídico e lipídico em ratos. Rev. Nutr., Campinas, v.21, n.2, p. 129-136, mar., 2008.

FERNANDES, A. F., et al, Efeito da substituição parcial da farinha de trigo por farinha de casca de batata (Solanum Tuberosum Lineu). Ciênc. Tecnol. Aliment., Campinas, v.28, n.0, p.56-65, Dez., 2008.

FERREIRA, J.F. et.al. Biscoito de abóbora kabutiá com casca e bolo de banana caturra com casca: elaboração e análise sensorial. V Semana de Tecnologia em Alimentos, Ponta Grossa, v.2, n.1, 2007..

GONÇALVES, B.S. O Compromisso das empresas com o combate ao desperdício de alimentos: banco de alimentos, colheita urbana e outras ações. São Paulo: Instituto Ethos, 2005. 10p. Disponível em: http:www.internethos.org.br. Acesso em 20/07/2009.

GONDIM, J. A. M. et al, Composição centesimal e de minerais em cascas de frutas. Ciênc. Tecnol. Aliment., Campinas, v.25, n.4, p.825-827, out., 2005. 
GOULART, R. M.M. Avaliação de um programa de aproveitamento de alimentos. Rev. Integração., n.46, p. 291-294, jul.,2006.

MEZOMO,I.F.deB. Os Serviços de Alimentação: Planejamento e Administração. 1 ed, São Paulo: Manole, 2002,16-27p.

MOURA, D. D. B.; VILELA, G. de B. J. Hábitos alimentares e qualidade de vida. Revista do Centro de Pesquisas Avançadas em Qualidade de Vida. Ponta Grossa, v.1, n.2, 2009.

PARISENTI, J.; FIRMINO, C .C.; GOMES, C. E.; Avaliação de sobras de alimentos em unidade produtora de refeições hospitalares e efeitos da implantação do sistema de hotelaria. Alim. Nutr., Araraquara, v.19, n.2, p. 191-194, abr., 2008.

SANTANA, A. F., OLIVEIRA, L. F. Aproveitamento da Casca de Melancia (Curcubita citrullus, Shrad) na Produção Artesanal de Doces Alternativos. Alim. Nutr., Araraquara, v.16, n.4, p 363 - 368, Out., 2005.

SANTOS, A.V. Obtenção e incorporação de farinha de casca de maracujá na produção de bolos de chocolate. 2008. 105f. Dissertação (Mestrado em Engenharia de Processos) Universidade Tiradentes -UNIT Aracaju, Sergipe.

SOUZA, P. D. J. et al, Análise sensorial e nutricional de torta salgada elaborada através do aproveitamento alternativo de talos e cascas de hortaliças. Alim. Nutr., Araraquara, v.18, n.1, p. 55-60, Jan., 2007.

TEIXEIRA, E. L. et al. Aproveitamento Integral dos Alimentos e a Saúde Social. Disponível em: http://www.pr5.ufrj.br/cd_ibero/biblioteca. Acesso em 13/08/09.

UCHOA, A. M. A. et al, Parâmetros Físico-Químicos, Teor de Fibra Bruta e Alimentar de Pós Alimentícios Obtidos de Resíduos de Frutas Tropicais. Segurança Alimentar e Nutricional, Campinas, v.15, n.2, p. 58-65, 2008

VAZ, C.S. Restaurantes - controlando custos e aumentando lucros. Brasília, 2006, 196p. 